\title{
Perceptions of church leaders on accessibility and affordability of alcohol abuse amongst youth in Musina Town, Limpopo province
}

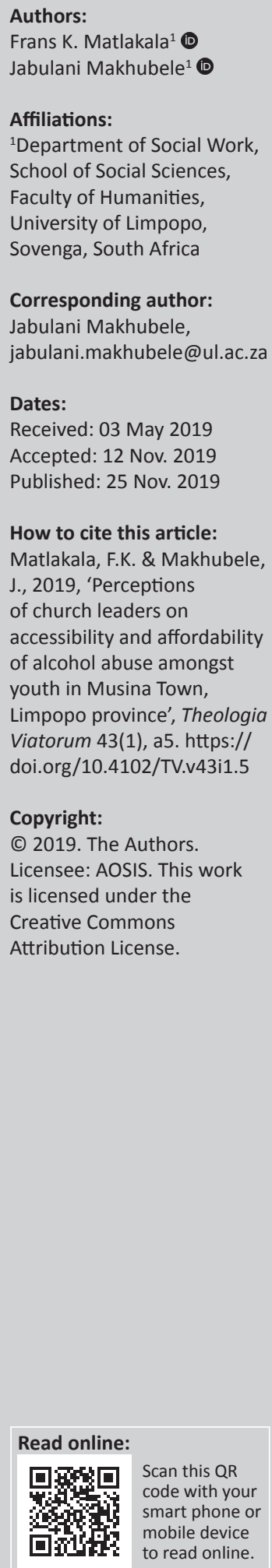

\begin{abstract}
Alcohol abuse is associated with numerous risk factors amongst the youth. The youth indulge in binge drinking because of social exclusion, and accessibility and affordability of alcohol, especially in rural areas. As such, many countries including South Africa spend a large amount of money on drug prevention programmes for the youth. This study was aimed at exploring the perceptions of church leaders on accessibility and affordability of alcohol abuse amongst youth in Musina Town, Limpopo province, South Africa. An exploratory research design was utilised. The study population was drawn from male church leaders at Musina Town. The purposive sampling approach was employed in this article. Qualitative approaches and semi-structured interviews were used to collect the data. Data were analysed thematically using NVivo software. The study revealed that negligence of parents, pressure from peers and early debut of alcohol abuse because of poor legislation enforcement predispose the youth to indulge in binge drinking and thus play a significant role in influencing the youth's decision to use alcohol. The findings of the study point to the disbursement of funds for research purposes, in particular to social work scholars, to do more research on risk factors of alcohol abuse in deep rural areas.
\end{abstract}

Keywords: alcohol abuse; perception; youth; legislation; peer pressure.

\section{Introduction}

South Africa in general and its provinces in particular are widely affected by the effects of alcohol abuse amongst the youth. Alcohol outlets are in abundance, especially in rural areas, as they are seen as a way of addressing one social issue which is unemployment. In support, several researchers have observed that the youth in rural areas indulge in alcohol abuse more than their counterparts in urban areas (Lambert, Gale \& Hartley 2008; Lasser et al. 2010; Matlakala 2018). The reason for high alcohol consumption in rural areas is attributed to high density of alcohol outlets (Connor et al. 2010). Alcohol consumption is not an issue; however, alcohol abuse is a challenge and continues to be a global challenge, especially amongst the youth (Department of Social Development [DSD] 2013). It is for this reason that many countries spend a large amount of money annually on drug prevention programmes for the youth (United Nations Office on Drugs and Crime 2008). Earlier findings by Shilakwe (2005) pointed out that R20 billion is spent annually on drug abuse programmes in South Africa. Ultimately, many countries including South Africa lose funds that could be used in poverty alleviation programmes. In fact, Makhubele (2012) discovered that there is a link between alcohol abuse and poverty. To this end, the present study sought to explore the perceptions of church leaders on accessibility and affordability of alcohol abuse amongst youth in Musina Town, Limpopo province, South Africa.

\section{Background information and problem formulation}

Behaviours such as alcohol abuse and risky sexual behaviour have the potential to undermine the health and development of the youth. These behaviours are commonly interrelated and unfortunately often continue into adulthood (Centers for Disease Control and Prevention 2006). These factors warrant further investigation, more especially in rural areas. Lambert et al. (2008), Gfroerer, Larson and Colliver (2007) and Lasser et al. (2010) have discovered that the geographical setting influences alcohol abuse amongst the youth. On the same note, Masemola, Van Aardt and Coetzee (2012) and Matlakala, Makhubele and Mafa (2019b) have propounded that alcohol abuse depends on the environment in which the youth find themselves. It is for this reason that Matlakala (2018) declared that youth in their environment are enticed by alcohol advertisements that are portrayed by media. In corroboration, Matlakala et al. (2019b) state that advertisements on media induce an attitude of youth by pairing an unconditioned stimulus with a conditioned 
stimulus. For instance, alcohol is paired with an exquisite lady which makes the youth believe that drinking alcohol will make a young person loved by girls. As such, the authors acknowledge that high density, lack of guardians, disposer of alcohol outlets through media and lack of recreational facilities in rural areas contribute to excessive use of alcohol amongst the youth.

According to Patrick, Maggs and Osgood (2010) and Mafa et al. (2019), students indulge in alcohol abuse when they are in taverns, at parties and other entertainment events on campus, which are more likely to be on weekends. Moreover, Finlay et al. (2012) opined that students in tertiary institutions are likely to indulge in alcohol abuse during weekends. It could be deduced that because of the lack of guardianship and lectures to attend, students view this as an open window to visit entertainment areas in order to de-stress. Furthermore, students choose cheaper alcoholic beverage to maximise their alcohol intake for monetary reasons (Ayuka, Barnett \& Pearce 2014). As such, Wagenaar, Salois and Komro (2009) and Sharma, Sinha and Vandenberg (2017) propounded that an increase in alcohol prices and tax leads to a decrease in alcohol intake. This approach was adopted in South Africa when, in his Budget Speech (2018), the then Minister of Finance, Malusi Gigaba, announced that value added tax (VAT) would increase by $1 \%$ from $14 \%$ to $15 \%$ in order to reduce alcohol consumption amongst the youth.

\section{Research methodology}

In this article, the researchers used qualitative and exploratory research designs to unpack risk factors of alcohol abuse amongst the youth. Creswell (2003) asserts that a qualitative approach assists researchers in gaining first-hand information from the participants. On the contrary, Neuman (2000) avers that the exploratory design seeks to address a phenomenon that is less studied. To this end, seven church leaders from Musina Town were purposively sampled to participate in the study because of their availability. Furthermore, the researchers were of the view that church leaders assume parental responsibilities for the youth and, therefore, might be in the best position to know the risk factors of alcohol abuse amongst them. In support, Matlakala et al. (2019a:5) aver that 'church leaders engage with youth and parents at different levels and platforms.' Semi-structured interviews were conducted with participants until the study reached the level of saturation. The data were thematically analysed using NVivo software. According to Braun and Clarke (2006:4), thematic analysis is a 'rarely-acknowledged, yet widely-used qualitative analytic method within social science arena.' Therefore, thematic analysis was used in this study because of its ability to produce well-structured themes.

\section{Ethical consideration}

De Vos et al. (2011:63) define ethics as 'moral principles that are widely accepted and offer behavioural expectations about conduct within the profession.' Moreover, Krogsrud-Miley, O'Melia and DuBois (2001) aver that researchers should execute studies ethically and responsibly. In terms of the observation of ethical codes, the participants did not display any behaviours that caused harm during data collection. However, the researchers were ready to refer them to an area social worker for a debriefing service had they displayed behaviour causing harm during their participation. Ethical permission to conduct the study was obtained from Turfloop Research and Ethics Committee of the University of Limpopo.

\section{Findings and discussion Learning from parents}

A great majority of the participants in the study indicated that young people indulge in alcohol abuse because of learnt behaviour from their parents. Some of the responses made were as follows:

'I already got on the wrong side of the other one, I asked him if whether he knows that when he drinks in front of the children, they will end up drinking?' (Participant 2, male, Pastor)

\section{Others echoed:}

'Children learn drinking from their parents.' (Participant 6, male, Pastor)

'As parents, when your child asks for money you should ask what is that he or she wants to buy, and you should have a look at what he or she bought on his or her return.' (Participant 7, male, Pastor)

The findings show that whenever an authoritarian figure engages in maladaptive behaviours, such as the consumption of alcohol, in the presence of a minor, it is likely that the minor would emulate the elderly person as he or she perceives them as the role model. This finding affirms that a young person's home is like an institution where primary socialisation takes place (DSD 2013). In other words, family has the role to mentor and teach young people to not engage in excessive drinking. However, in most rural areas, young people grow up in families that excessively abuse alcohol and youths see that as an acceptable behaviour (Rapholo et al. 2019). According to Matlakala et al. (2019b), youths lack role models and discipliners as they indulge in alcohol abuse with their parents. In this study, the participants acknowledged that parents should be careful about their own conduct when children and youth are present. As such, the researchers are of the view that a change in parents' conduct will result in a decline in alcohol abuse amongst youth. In other words, young people will be learning and emulating positive and good behaviour from their parents.

\section{Permissive parents}

A substantial majority of the participants reported that parents are ignorant and are not taking good care of their children. They believed that the youth indulge in alcohol abuse because there is no visible adult supervision around them. Some of the responses given by the participants were as follows:

'Parents are irresponsible, we leave our children alone in the RDP house (Reconstruction and Development Programme) and 
go to work. I am still saying, we should not leave children by themselves.' (Participant 1, male, Pastor)

\section{Others said:}

'Some parents leave their children to go to work early in the morning.' (Participant 3, male, Pastor)

'We as parents are irresponsible.' (Participant 7, male, Pastor)

The participants were of the view that lack of guardians also tempts the youth to indulge in alcohol abuse because there is no one who supervises their behaviour and movement. This finding substantiates the findings of Lloyd and Anthony (2003) that alcohol consumption is linked with inadequate adult supervision of children during early adolescence and late childhood. In addition, DSD (2013:19) states that 'adolescents with parents who held permissive attitudes towards alcohol use are more likely to engage in heavy binge drinking.' In each family, the absence of adult personnel creates avenue for maladaptive behaviours. An example is a university, where there is minimal supervision by parents. As a result, young people maximise the opportunity to indulge in binge drinking and other substance abuse. This example was also emphasised by Bachman et al. (2013), who discovered that increased alcohol consumption, especially in secondary schools, is linked to permissive parenting and lack of supervision by the elderly. In other words, the onset of binge drinking corresponds to secondary school years. Therefore, with lack supervision from parents young people party until late. This is where the youth start to engage in binge drinking. Given the above discussion, Africans, especially those who are in rural areas, need to ask their extended family members to provide guardianship to their children if they are working and residing in urban areas in order to lessen alcohol abuse.

\section{Peer pressure}

The majority of the participants believed that children not only learn from their parents but also learn from their friends to indulge in alcohol abuse. Some of the responses were as follows:

'Children learn these things from the streets, for example, I am a pastor, I do not smoke, drink alcohol nor there is anyone in my house who does those things, but you will find your child drinking, where does he learn that behaviour from? From the streets, he left home and went on to learn these things from the streets.' (Participant 3, male, Pastor)

Another echoed:

'Young people drink alcohol so they can make their friends happy.' (Participants 6, male, Pastor)

From the above findings, it could be deduced that youths engage in binge drinking because of the company they keep. According to the United Nations on Drugs (2004), youths indulge in alcohol abuse for different reasons, such as seeking a sense of belonging to a certain group, coping with school stress and searching for identity. Be that as it may, Thrul and Kuntsche (2015) propounded that the company that young people find themselves in determines the behaviour that they will emulate. In expatiating the latter view, Robinson et al. (2016) reported that youths consume alcohol because of the negative friends that they have kept in their lives. From the above discussion, it could be suggested that alcohol abuse is learnt from the company that one keeps. If peers are vigilant in choosing their friends, they are more likely to learn and emulate a good conduct. This assumption is supported by Rapholo et al. (2019) who averred that young people need to be vigilant when choosing friends.

\section{Early debut of alcohol abuse}

The majority of the participants were of the view that children debut early to alcohol abuse because of poor legislation enforcement. Some of their responses were as follows:

'Children of this era drink alcohol by ages of 9 to 10 years ....' (Participant 3, male, Pastor)

In corroboration another said:

'We, whom travel to work by bus in the morning, see it all. On the street we find and see young people drunk ....' (Participant 4, male, Pastor)

The findings indicate that young people start to indulge in alcohol as early as they reach the age of 9 years. For this reason, the researcher believes that legislations regulating substance use are good on paper and poor in implementation. For instance, subsections 1 and 3 of Section 10 of the Liquor Act 53 of 2003 stipulate that:

[A] person must not sell or supply liquor or methylated spirits to a minor and a person must take reasonable measures to determine accurately whether a person is a minor, before selling or supplying liquor or methylated spirits to that person. (South Africa 2003:15)

In South Africa, a minor is referred to as someone who is under the age of 18 years. This is supported by the Children's Act 38 of 2005 (South Africa 2005). However, during the discussion to amend the Liquor Act 53 of 2003, it was argued that 'the national minimum legal age at which alcohol can be purchased and consumed should be raised from eighteen (18) to twenty-one (21) years' (South Africa 2016:8). Section 8 of the Liquor Act is not applicable in rural areas where bar owners chase profit at the expense of minors.

Subsection (1) (iii) of Section 9 of the Liquor Act 53 of 2003 stipulates that a person 'must not advertise in a manner intended to target or attract minors' (South Africa 2003:8). With respect to the above provision, Thobejane and Raselekoane (2017:96) observed that 'alcohol advertisement always shows the good side of drinking alcohol and the age restriction is shown in small letters.' Moreover, what is troubling is the fact that most of these advertisements always portray men who drink alcohol as being strong. The youth who watch television see this as a motivation to drink so that they do not appear weak and timid in front of their peers. This indicates that the Liquor Act 53 of 2003 is legitimate or ideal on paper but poor in implementation. 


\section{Affordability of alcohol}

The religious leaders were asked on their views of affordability of alcohol in their community. The majority of them stated that youths indulge in binge drinking because alcohol is affordable. The following are some of the views shared by the participants:

'Alcohol is very cheap in our community; it is like a competition, in every street there is a tavern and this people make their beers cheap to steal each other's customers.' (Participant 1, male, Pastor)

\section{Another echoed:}

'They like cheap alcohol, they do not mind sharing one Black Label because they say it is cheap.' (Participant 5, male, Pastor)

From the above findings it could be deduced that young people indulge in alcohol abuse because of its affordability in their community. Wagenaar et al. (2009), Xu and Chaloupka (2011) and Matlakala (2018) are all in agreement with the fact that an increase in alcohol prices leads to a decrease in alcohol consumption. Furthermore, Ayuka et al. (2014) found that drinkers tend to choose cheaper alcoholic beverages to maximise their alcohol intake for monetary reasons. Also, Williams et al. (2019) demonstrated that affordability of alcohol is responsible for binge drinking amongst the youth. The researchers are of the opinion that the youth cannot afford expensive alcohol because most of them are either unemployed or in tertiary institutions and dependent on their parents. In other words, there will be decline in alcohol consumption when VAT increase from $14 \%$ to $15 \%$ as propounded by the then Minister of Finance, Malusi Gigaba, in his 2018 budget speech. As already discussed, the youth might reduce alcohol consumption because of the increase in alcohol pricing.

\section{Conclusion}

Alcohol abuse amongst the youth has been a contributing factor to social problems. The analysis in this article has indicated that parental influence, peer pressure and early debut because of poor law enforcement play a significant role in influencing the youth's decision to use alcohol. The fact that majority of social issues emanate from alcohol abuse means that the government, along with other stakeholders, needs to work hand in glove to ameliorate the risk factors of alcohol binge drinking amongst the youth. As such, the accessibility and affordability of alcohol abuse influence the behavioural change amongst the youth, which later encourages maladaptive behaviours (such as heavy episodic drinking at parties) amongst the youth. Although legislations are in place, they lack strict implementation. This shows that policymakers need to relook at their implementation to deal with this global issue. The Liquor Amendment Bill should be implemented so it could strengthen the Liquor Act 53 of 2003. To that end, the findings of this study point to the disbursement of funds for research purposes, in particular to social work scholars to do more research on risk factors of alcohol abuse in deep rural area.

\section{Acknowledgements}

The authors would like to thank the National Research Foundation for providing funding for this study.

\section{Competing interests}

The authors have declared that no competing interests exist.

\section{Authors' contributions}

F.K.M. collected the data and reviewed the literature. Both Prof. J.C.M. and F.K.M. analysed the data and worked together on the write-up of the article.

\section{Funding information}

This study was funded by the National Research Foundation.

\section{Data availability statement}

Data sharing is not applicable to this article as no new data were created or analysed in this study.

\section{Disclaimer}

The views and opinions expressed in this article are those of the authors and do not necessarily reflect the official policy or position of any affiliated agency of the authors.

\section{References}

Ayuka, F., Barnett, R. \& Pearce, J., 2014, 'Neighbourhood availability of alcohol outlets and hazardous alcohol consumption in New Zealand', Health \& Place 29, 186-199. https://doi.org/10.1016/j.healthplace.2014.07.002

Bachman, J.G., Wadsworth, K.N., O'Malley, P.M., Johnston, L.D. \& Schulenberg, J.E., 2013, Smoking, drinking, and drug use in young adulthood: The impacts of new freedoms and new responsibilities, Lawrence Erlbaum, Mahwah, NJ.

Braun, V. \& Clarke, V., 2006, 'Using thematic analysis in psychology', Qualitative Research in Psychology 3(2), 77-101. https://doi.org/10.1191/1478088706qp0630a

Centers for Disease Control and Prevention (CDC), 2004, National Center for Injury Prevention and Control (NCIPC). Web-Based Injury Statistics Query and Reporting System (WISQARS), viewed 06 June 2018, from http://www.cdc.gov/ncipc/ wisqars/default.htm.

Connor, J.L., Kypri, K., Bell, M.L. \& Cousins, K., 2010, 'Alcohol outlet density, levels of drinking and alcohol-related harm in New Zealand: A national study', Journal of Epidemiology \& Community Health 65(10), 841-846. https://doi.org/10.1136/ Epidemiology \& Com

Creswell, J., 2003, Research design: Qualitative, quantitative and mixed methods approaches, 2 nd edn., Sage, Thousand Oaks, CA.

Department of Social Development [DSD], 2013, Substance use, misuse and abuse amongst the youth in Limpopo Province, Government Print, Limpopo.

De Vos, A.S., Strydom, H., Fouché, C.B. \& Delport, C.S.L., 2011, Research at grass roots: For the social sciences and human service professions, 4th edn., Van Schaik Publishers, Pretoria.

Finlay, A.K., Ram, N., Maggs, J.L. \& Caldwell, L.L., 2012, 'Leisure activities, the social weekend, and alcohol use: Evidence from a daily study of first-year college students', Journal of Studies on Alcohol and Drugs 73(2), 250-259. https://doi. org/10.15288/jsad.2012.73.250

Gfroerer, J.C., Larson, S.L. \& Colliver, J.D., 2007, 'Drug use patterns and trends in rural communities', The Journal of Rural Health 23(s1), 10-15. https://doi.org/10.1111/ j.1748-0361.2007.00118.x

Krogsrud-Miley, K. O'Melia, M. \& DuBois, B., 2001, Generalist social work practice: An empowering profession, Allyn \& Bacon, Boston.

Lambert, D., Gale, J.A. \& Hartley, D., 2008, 'Substance abuse by youth and young adults in rural America', The Journal of Rural Health 24(3), 221-228. https://doi. org/10.1111/j.1748-0361.2008.00162.x

Lasser, J., Schmidt, E., Diep, J. \& Huebel, A., 2010, 'Underage rural drinking: Survey data and implications for educators', Rural Educator 31(3), 38-46.

Lloyd, J.J. \& Anthony, J.C., 2003, 'Hanging out with the wrong crowd: How much difference can parents make in an urban environment?', Journal of Urban Health 80(3), 383-399. https://doi.org/10.1093/jurban/jtg043 
Mafa, P., Makhubele, J.C., Ananias, J.A., Chilwalo, B.N., Matlakala, F.K., Rapholo, S.F. et al., 2019, 'Perception of church leaders on the risk factors associated with alcohol abuse amongst the youth in Musina Town: Implications for policy considerations.' Global Journal of Health Science 11(2), 92-101.

Makhubele, J.C., 2012, 'Social exclusion as a contributing factor for the addition of harmful substances to home-made alcohol: The case of Mopani District in Limpopo Province, South Africa', African Journal of Drug and Alcohol Studies 11(1), 17-27.

Masemola, E., Van Aardt, C.J. \& Coetzee, M.C., 2012, Income and expenditure of household in South Africa: Research report 429, The Bureau of Market Research (BMR), University of South Africa (UNISA).

Matlakala, F.K., 2018, 'Risk factors of alcohol abuse amongst the youth in Musina town, Limpopo province', Masters' dissertation, University of Limpopo, Limpopo.

Matlakala, F.K., Makhubele, J.C., Hasheela, M.W., Ananias, J.A., Rapholo, S.F., Svinurai, A. et al., 2019a, 'Religious leaders perspective on the effects of 'Hitting the Bottle Hard' amongst the youth in Musina Town, Limpopo Province', e-Bangi Journal of Social Sciences and Humanities 16(4), 1-11.

Matlakala, F.K., Makhubele, J.C. \& Mafa, P., 2019b, 'Psychosocial and demographic factors compounding to alcohol abuse amongst youth: A case study of Musina High School', Global Journal of Health Sciences 11(7), 69-79. https://doi.org/10.5539/gihs.v11n7p69

Neuman, W.L., 2000, Social research methods: Qualitative and quantitative approaches, 4th edn., Allyn \& Bacon, Boston, MA.

Patrick, M.E., Maggs, J.L. \& Osgood, D.W., 2010, 'Late Night Penn State alcohol-free programming: Students drink less on days they participate', Prevention Science 11(2), 155-162. https://doi.org/10.1007/s11121-009-0160-y

Rapholo, S.F., Makhubele, J.C., Ananias, J.A., Svinurai, A., Hasheela, M.W., Hamuse, T.N.I. et al., 2019, 'Non-governmental organisations personnel, social workers and religious leaders' perspectives on the risk factors of alcohol abuse amongst the youth: The case of the northern region of the Republic of Namibia', Global Journal of Health Science 11(12), 55-64. https://doi.org/10.5539/gjhs.v11n12p55

Robinson, E., Oldham, M., Sharps, M., Cunliffe, A., Scott, J., Clark, E. et al., 2016, 'Social imitation of alcohol consumption and ingratiation motives in young adults', Psychology of Addictive Behaviors 30(4), 442. https://doi.org/10.1037/adb0000150
Sharma, A., Sinha, K. \& Vandenberg, B., 2017, 'Pricing as a means of controlling alcohol consumption', British Medical Bulletin 123(1), 149-158. https://doi.org/10.1093/ $\mathrm{bmb} / \mathrm{ldx} \mathrm{O} 20$

Shilakwe, D., 2005, 'The effects of parental alcohol abuse on children', Doctoral dissertation, Masters Dissertation, University of Venda.

South Africa., 2003, Liquor Act 53 of 2003, Government Printer, Cape Town.

South Africa., 2005, Children's Act 38 of 2005, Government Printer, Pretoria.

South Africa., 2016, Liquor Amendment Bill, Government Printer, Pretoria.

Thobejane, T. \& Raselekoane, R., 2017, 'Probing alcohol abuse amongst the youth of Musina Community in Limpopo Province of South Africa', Studies of Tribes and Tribals 15(2), 94-102. https://doi.org/10.1080/0972639X.2017. 1413799

Thrul, J. \& Kuntsche, E., 2015, 'The impact of friends on young adults' drinking over the course of the evening - An event-level analysis', Addiction 110(4), 619-626. https://doi.org/10.1111/add.12862

United Nations Office on Drugs and Crime, 2008, Annual report, viewed 29 March 2017, from http://www.unodc.org/documents/about-unodc/ AR08WEB.PDF.

United Nations on Drugs, 2004, World drug report 2004, vol. 1, United Nations Publications, Oxford University Press, Herndon, VA.

Wagenaar, A.C., Salois, M.J. \& Komro, K.A., 2009, 'Effects of beverage alcohol price and tax levels on drinking: A meta-analysis of 1003 estimates from 112 studies', Addiction 104(2), 179-190. https://doi.org/10.1111/j.1360-0443. 2008.02438.x

Williams, P.P, Morojele, N., Londani, M., Harker-Burnhams, N. \& Parry, C.D., 2019 'Alcohol advertising, affordability and availability, and the effect on adult heavy drinking and symptoms of alcohol problems: International alcohol control study (South Africa)', Substance Use \& Misuse 54(11), 1-12.

Xu, X. \& Chaloupka, F.J., 2011, 'The effects of prices on alcohol use and its consequences', Alcohol Research \& Health 34(2), 236. 